\title{
Koronoid çıkıntı kırıkları
}

\section{Fractures of the coronoid process}

\author{
Burak Yağmur Öztürk¹, Umut Akgün² \\ ${ }^{1}$ Niğde Devlet Hastanesi, Niğde \\ ${ }^{2}$ Acıbadem Üniversitesi Tıp Fakültesi, Ortopedi ve Travmatoloji Anabilim Dalı, İstanbul
}

Koronoid kırığına bağlı dirsek instabilitesinin eşlik ettiği kompleks yaralanmalar, yüksek oranda eklem sertliği, artroz, tekrarlayıcı instabilite ve kaynamama gibi komplikasyon riski bulunan, tanı ve tedavisi zor yaralanmalardır. Benzer yaralanmalarda başarılı sonuç elde edilmesi özellikle koronoid parçanın başarılı redüksiyonuna bağlıdır. Cerrahi başarı için bölgenin kompleks biyomekanik ve anatomik özelliklerine hakim olmak gerekmektedir.

Anahtar sözcükler: koronoid kırı̆̆ı; dirsek; çıkıklar
Coronoid fractures associated with elbow instability represent a challenging injury group with a high incidence of complications such as stiffness, arthrosis, recurrent instability and malunion. Successful outcome mostly depends on the anatomic reduction of the coronoid fragment. One must know the complex biomechanics and the anatomy of the elbow in order to obtain the best possible results in surgery.

Key words: coronoid fracture; elbow; dislocations
K oronoid çıkıntı kırıkları \%5 ila \%10 oranında izlenen; genellikle dirsek çıkıkları veya kırıkı-çıkıkları ile birliktelik gösteren nadir kırıklardır. ${ }^{[1]} \mathrm{Bu}$ kırıklar, tipik olarak dirsek posteriora çıkarken koronoidin distal humerus üzerinde maruz kaldığı makaslama kuvveti sonucu oluşur. ${ }^{[2]}$ Koronoid, büyük sigmoid çentiğin distal kısmı üzerindeki yerleşimi sayesinde takoz görevi yaparak, ulnanın posteriora çıkmasını engelleyen primer kemik yapıdır. Anterior eklem kapsülü ve brakiyaliste koronoid ucunun distaline yapışır. Mediyale doğru uzanan sublim tüberküle ise mediyal kollateral bağın anterior demeti yapışır. Ayrıca koronoid, anteromediyal kısmı ile dirseğin posteromediyal rotasyonel stabilitesine katkıda bulunur. ${ }^{[3]}$ Koronoid ucunun anterior kapsülün yapışma yeri olması dışında eklem stabilitesinde önemli bir etkisinin olmadığı düşünülmektedir. ${ }^{[4]}$ Posterior kuvvetlere direnç gösteren birincil yapı olduğu için, koronoid fragmanın büyük olduğu kırıklarda, sık görülen bir kronik instabilite tipi olan posterior dirsek subluksasyonu meydana gelmektedir. Buradaki mekanizma, normalde eklem üzerine posterior yönde etkiyen kuvvetleri karşılayacak olan anterior desteğin kaybıdır (Şekil 1). Benzer şekilde sublim tüberkül ve anteromediyal koronoid kırıkları da, varus ve posteromediyal instabiliteye yol açmaktadır.

Temel olarak koronoid parçada kemik lezyona neden olan üç farklı mekanizma tanımlanabilir:

1) Valgus veya saf posterior yüklenme nedeni ile koronoid ucunun troklea üzerine yaslanması ile kırılması. Radyolojik incelemelerde izole koronoid uç kırığı izlenmesi, mutlaka geçirilmiş bir subluksasyon veya çıkığın göstergesidir.

2) Valgus ile birlikte posterolateral yüklenme nedeni ile oluşan 'korkunç üçlü' (çıkık + radius başı kırığı + koronoid kırı̆ğ + kollateral bağ lezyonu).

3) Varus ile birlikte posteromediyal yüklenme nedeni ile ortaya çıkan koronoid mediyal faset kırıkları. Bu farklı yaralanmaların oluş mekanizmalarında açık kol üzerine düşme sırasında ön kol pozisyonunun belirleyici olduğu düşünülmektedir. Ön kol supinasyonda iken meydana gelen darbelerde mekanizma 'korkunç üçlü' yönünde gelişirken, ön kol pronasyonda iken meydana gelen darbelerde ise mekanizma varus-posteromediyal yaralanmalara neden olmaktadır.

- İletişim adresi: Dr. Umut Akgün, Acıbadem Üniversitesi Tıp Fakültesi, Ortopedi ve Travmatoloji Anabilim Dalı, İstanbul Tel: 0532 - 7942288 e-posta: umut.akgun@acibadem.edu.tr

- Geliș tarihi: 10 Ocak 2014 Kabul tarihi: 10 Ocak 2014 


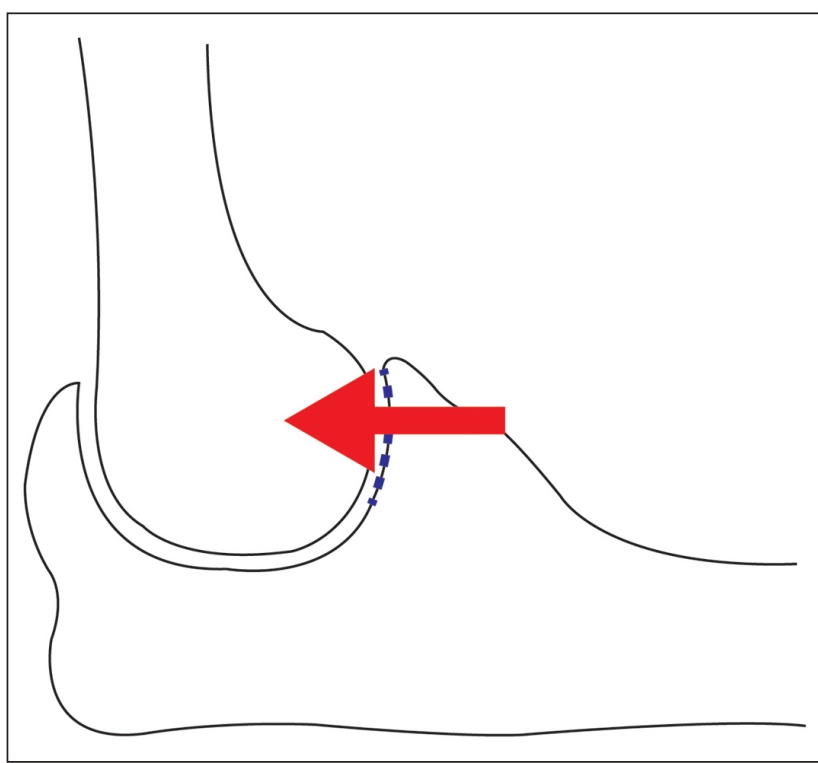

Şekil 1. Koronoid çıkıntı, dirsek ekleminde posterior yönde oluşan kuvvetlere karşı koyacak şekilde bir takoz etkisine sahiptir.

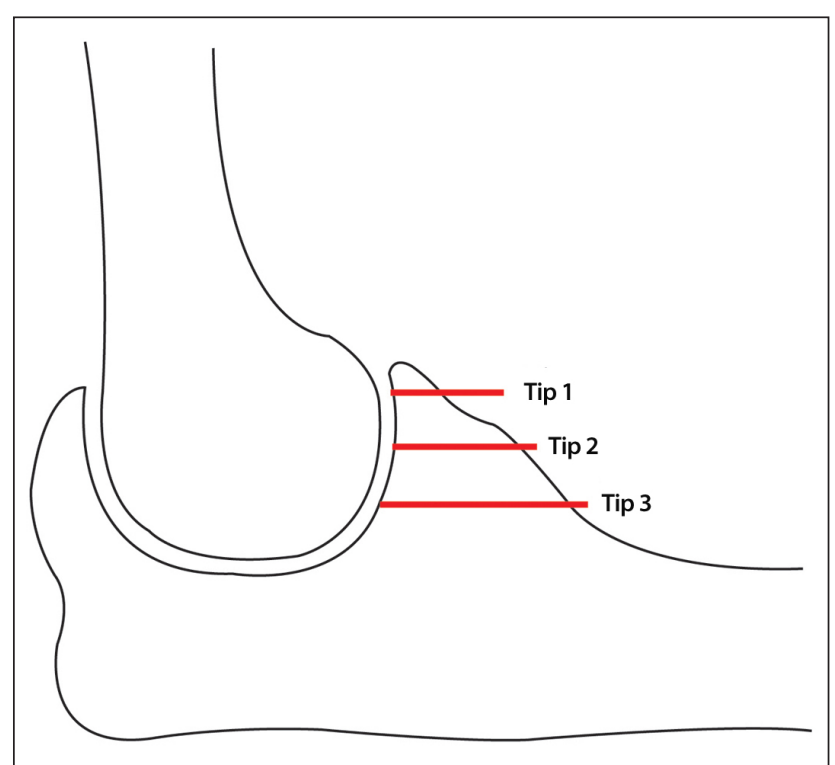

Şekil 2. Regan ve Morrey sınıflandırması: Tip I, koronoid ucu kırıkları; Tip II, koronoid çıkıntının \%50'den azını içeren kırıklar; Tip III, koronoid çıkıntının \%50 ve fazlasını içeren kırıklar.
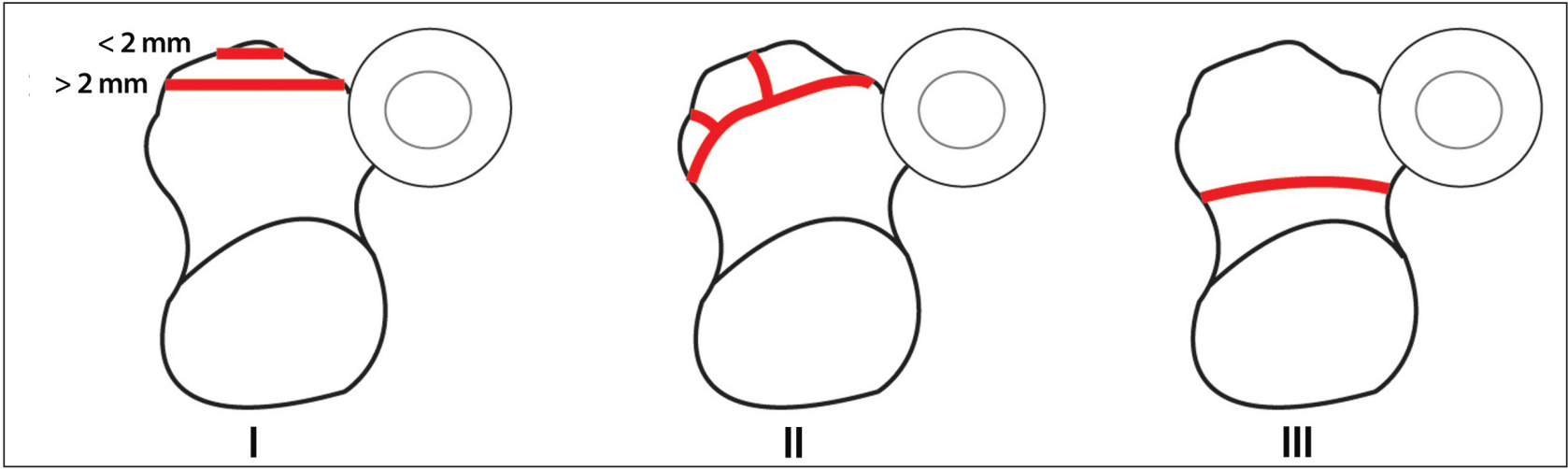

Şekil 3. O'Driscoll sınıflaması: Tip I, koronoid ucu kırıkları (Altgrup I, kırık yüksekliği $\leq 2$ mm; Altgrup II, kırık yüksekliği >2 mm); Tip II, anteromediyal koronoid kırıkları (Altgrup I, izole anteromediyal kenar; Altgrup II, anteromediyal kenar + uç; Altgrup III, anteromediyal kenar + uç + süblim tüberkül); Tip III, koronoid basis kırıkları (Altgrup I, izole koronoid; Altgrup II, koronoid + transolekranon).

Dirsek kırıklı çıkıklarında, stabilitenin sağlanması ve eklem fonksiyonlarının korunabilmesi açısından koronoid kırıklarının uygun tanı ve tedavisi önemlidir. Başarısız sonuçların önemli bir kısmı, göz ardı edilen koronoid lezyonlarına bağlı olarak gelişmektedir.

\section{KIRIK SINIFLANDIRMASI VE EŞLIK EDEN YARALANMALAR}

Koronoid kırıkları için genellikle iki tip sınıflama kullanılmaktadır. Regan ve Morrey ${ }^{[5]}$ koronal planda, koronoid çıkıntıda meydana gelen kırık parçanın boyutuna göre sınıflama tanımlamışlardır (Şekil 2). Önceleri avulsiyon kırı̆̆ı olarak da tariflenen Tip I kırık, aslında dirsek subluksasyonu veya çıkığı sırasında oluşan bir makaslama yaralanmasıdır ve koronoid boyunun \%10'undan azını ilgilendirir. Tip II kırık koronoid boyunun yaklaşık \%50 kadarını, Tip III kırık ise \%50'den fazlasını içeren ve parçalı olabilen, bağ yaralanması ve instabiliteyle birlikte görülme olasılığı yüksek olan kırık tipleridir. Aynı yazarların 35 hastalık serisinde dirsek çıkığı insidansı Tip I kırıklarda \%28, Tip II'de \%37 ve Tip III'te $\% 80$ olarak bildirilmiştir.

O'Driscoll[6] sınıflamasında ise koronoid kırıkları aksiyel kesitte değerlendirilerek üç gruba ayrılmıştır (Şekil 3). Birinci grup olan koronoid ucu kırıkları iki alt gruba ayrılır: Tip I, 2 mm'den az yükseklikte; Tip II ise 
2 mm'den fazla yükseklikteki kırıklardır. Bu gruptaki kırıklara hemen her zaman lateral kollateral bağ yaralanmasıyla beraber \%50 oranında mediyal kollateral bağ yaralanması ve dirsek çıkıkları eşlik eder. İkinci grup olan anteromediyal koronoid kırıklarının, varus posteromediyal rotasyon mekanizmasıla meydana geldiği ve lateral-mediyal yönde ilerleyen bir yumuşak doku hasarıyla beraber oluştuğu düşünülmektedir. Bu grupta yer alan kırıklar üç alt gruba ayrılır: Tip I, izole anteromediyal kenar kırığı; Tip II, buna ek olarak koronoid ucu kırığı; Tip III ise bunlara ek olarak sublim tüberkül kırığıdır. Varus posteromediyal rotasyon mekanizmasıyla oluşan anteromediyal koronoid kırıklarına genellikle lateral-kollateral bağ yaralanması eşlik ederken radius başı sağlam kalmaktadır. O’Driscoll sınıflamasındaki üçüncü grup kırıklar ise koronoid yüksekliğinin \%50'den fazlasını içeren basis kırıklarıdır. Basis kırıkları da iki alt tipe ayrılmaktadır: Tip I, izole basis kırığı; Tip II ise buna ek olarak transolekranon kırı̆̆ıdır. Bu kırıklar genellikle parçalı ve tespiti zor kırıklardır. Aksiyel anteroposterior travma (posterior çıkık mekanizması) nedeniyle oluşan bu gruptaki yaralanmalara sıklıkla radius başı kırıkları eşlik eder ve yetmezlik önce kemikte oluştuğu için beraberinde ciddi bağ yaralanmaları daha seyrek görülür.

\section{GÖRÜNTÜLEME}

Koronoid kırıklarının eşlik ettiği kompleks dirsek yaralanmalarında standart direkt grafiler genellikle tek başına yeterli değildir. Koronoid kırıklarının sınıflandırılması ve tedavi planlanması için bilgisayarlı tomografi (BT) ile elde edilmiş aksiyel, koronal ve sagittal kesitler değerlendirilmelidir. Üç boyutlu BT rekonstrüksiyonu, kırığın yapısının daha iyi anlaşılması ve cerrahi yaklaşım tercihi konularında yardımcı olabilir. Manyetik rezonans (MR) ise eşlik eden yumuşak doku yaralanmalarının değerlendirilmesinde yardımcı bir görüntüleme yöntemidir.

\section{TEDAVi}

İzole koronoid uç kırıklarında ( $\leq 2 \mathrm{~mm})$ konservatif tedavi mutlaka değerlendirilmelidir. Bu hasta grubunda karar vermede en önemli nokta dirsek stabilitesinin iyi değerlendirilmesidir. Zira izole kırıklar mutlaka bir dislokasyon veya subluksasyon sırasında meydana gelmektedir ve eşlik eden bağ yaralanmaları vardır. Anestezi altında skopi eşliğinde dirsek, hareket açıklığı boyunca muayene edilmeli, valgus ve varus streslerine karşı eklem uyumu iyi şekilde değerlendirilmelidir. Stabil bir dirsekte, izole koronoid uç kırıkları kısa süreli immobilizasyon sonrasında rehabilitasyon ile başarıyla tedavi edilmektedir. Tedavinin ilk haftalarında dirsek mutlaka stabilite yönünden düzenli olarak kontrol edilmeli ve direkt grafiler ile eklem uyumu kontrol edilmelidir.

Dirsek stabilitesinin bozulduğu tüm koronoid kırıklarında cerrahi tedavi endikasyonu öne çıkmaktadır. Koronoidin uç kısımı dışındaki kırıklarda gerek kemik stabilitesinin ileri derecede kaybı gerekse eşlik eden diğer yaralanmaların artması nedeni ile cerrahi tedavi gerekliliği artmaktadır.

Koronoid ve eşlik eden kompleks dirsek kırıklarının tespitinde, kırık cerrahisindeki temel prensipler geçerlidir. Stabil tespit için uygun cerrahi yaklaşımın seçilmesi çok önemlidir. Sırasıyla en derindeki kırıktan başlanarak (önce koronoid, sonra olekranon) redüksiyon ve tespit uygulanmasını takiben radius başı kırığı ve kollateral bağ yaralanması gibi eşlik eden durumlara tespit/tamir uygulanır. Koronoid çıkıntının fazla parçalanmadığı durumlarda vida veya plak uygulamaları yapılabilirken, çok parçalı kırıklarda osseöz tüneller sayesinde mevcut parçalar anterior kapsül ile birlikte tamir edilebilmektedir.

Koronoid çıkıntı kırıklarının eşlik ettiği yaralanmalarda cerrahi yaklaşım, posterior, anterior, mediyal veya lateral şekilde planlanabilir. Burada karar tamamen mevcut olguya özgün olmak durumundadır. Örneğin radius başının parçalı kırıldığı ve protez uygulanacak olguda lateral yaklaşımla öncelikle koronoid tespiti, takibinde radius başı protezi uygulanabilir. Farklı şekilde koronoid çıkıntı anteromediyal faset yaralanmalarına mediyal yaklaşım ile müdahale edilebilmektedir.

Sık görülen proksimal ulna/olekranon ve koronoid kırığına dirsek posterior instabilitesinin eşlik ettiği durumlarda direkt posterior yaklaşım tercih edilir. Bu yaklaşım proksimalde olekranon ucuna, distalde ise kırık tespiti için gerekli olan bölgeye kadar genişletilebilir. Bu bölümde örnek teşkil etmesi amacı ile posterior yaklaşım tarif edilecektir.

Tercihan hastaya kırık taraf üstte kalacak şekilde lateral dekübit pozisyon verilir. Kolun altına destek yerleştirilerek ekstremite serbest olacak şekilde ameliyat sahası içine alınır. Bu pozisyonda proksimal ulna, eklem ve radius başına ulaşım kolaydır. Ek olarak, proksimal ve posteriora yer değiştiren kırık fragmanı ve subluksasyonun redüksiyonu yerçekimi etkisiyle daha kolay hale gelir. Koronoid fragmana mediyal yaklaşım veya mediyal kollateral bağ tamiri gibi durumlar dışında, ulnar sinirin bulunarak izole edilmesine gerek yoktur. Bu noktada eşlik eden radius başı kırığına aynı yaklaşımla, ekstansör karpi radyalis brevisi laterale ekarte edip ankoneus kası liflerini sıyırdıktan sonra supinatör kası origosu komşuluğunda, ulna lateralinden 
ulaşılabilir (Şekil 4). Bu yaklaşımla, daha yüksek olan heterotopik ossifikasyon riskini azaltma amacıyla, radius başına ulaşmak için ayrı bir lateral Kocher insizyon da tercih edilebilir. Radius kırığının tespitini takiben koronoid redükte edilerek ulnar şafta tespit edilir. Bir veya (fragman büyüklüğünün yeterli olduğu durumlarda) tercihan iki adet parsiyel yivli kanüle lag vidası, lateral-distal girişle şaft üzerinden, koronoide doğru mediyal-proksimal doğrultuda gönderilir. Bu aşamada Doornberg ve arkadaşları ${ }^{[7]}$ tarafından tanımlandığı şekilde, koronoide ulaşmak için olekranon fragmanı ekarte edilerek daha rahat bir redüksiyon ve tespit imkanı sağlayan bir "görüş penceresi" yaratılır. Bu pencereden çalışılarak önce koronoid fragman tespit edilir, daha sonra olekranon kırığının tespiti tamamlanır. Koronoide daha direkt bir yaklaşımın gerektiği durumlarda kaslar ekarte edilerek ulna mediyal yüzünden disseksiyon gerçekleştirilebilir. Alternatif olarak ayrı bir anteromediyal insizyonla fleksör-pronatör kaslar ayrılarak ve ulnar sinir korunarak kırık hattına ulaşılabilir ve kırığa direkt redüksiyon uygulanabilir. Koronoid kırığının tespiti ardından proksimal ulnadaki kırık hattı da redükte edilerek lag vidaları ve düşük profilli bir posterior anatomik plak ile stabilize edilir. $\mathrm{Bu}$ aşamada, son yıllarda üretilen anatomik koronoid plakları da, kırığın vidalarla primer tespiti ardından bir destek plak olarak koronoid üzerine uygulanabilir. Floroskopik görüntüler ile kırık redüksiyonu ve eklem içinde implant olmadığının doğrulanmasından sonra kesi, katlar halinde kapatılır (Şekil 4).

Ameliyat sonrası ön kol nötral pozisyonda ve el bileği serbest olacak şekilde, $90^{\circ}$ fleksiyonda bir uzun kol
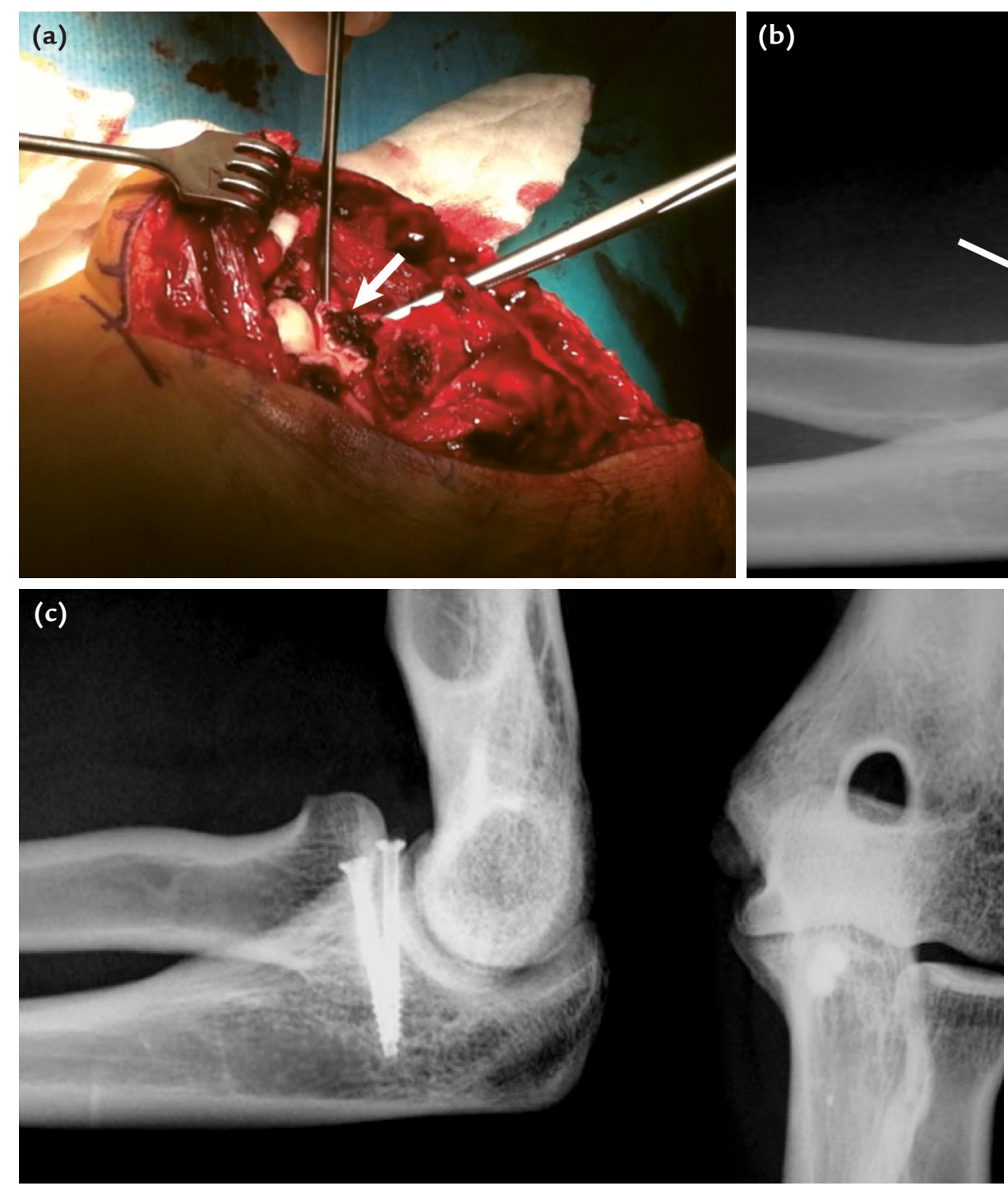

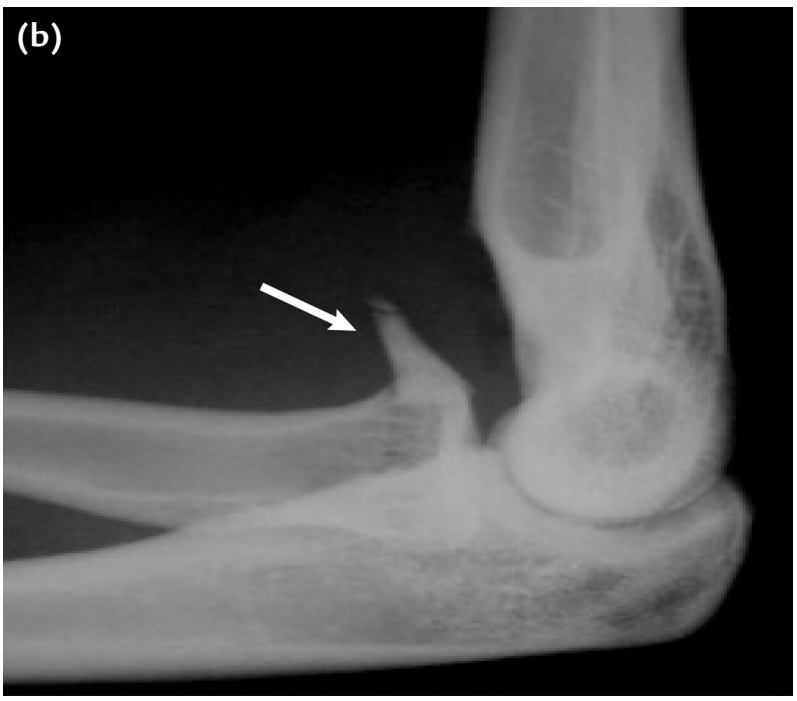

Şekil 4. a-c. Olekranon, koronoid ve radius başı parçalı kırık olgusu; sağ dirseğe posterior yaklaşım. Koronoid parça ok ile gösterilmektedir (a). Deplase izole koronoid basis kırığı olgusu, ameliyat öncesi lateral grafi (b). İki adet kanüle vida ile anteriordan tespit ardından, ameliyat sonrası grafileri (c) (Dr. Ufuk Nalbantoğlu' nun arşivinden). 
istirahat ateli 10 gün (dikişler alınana) kadar kullanılır. El bileği ve omuz hareketleri sınırlanmaz ve ilk gün hareketlere başlanır. Bu aşamayı takiben kırık stabilitesi ve hastanın durumu göz önüne alınarak, bir fizyoterapist eşliğinde pasif ve aktif destekli eklem açıklığı egzersizlerine (fleksiyon, ekstansiyon, ön kol rotasyonu) başlanabilir ve dördüncü haftadan itibaren aktif eklem açıklığı ve kuvvetlendirme egzersizleri ile rehabilitasyon sürdürülebilir.

\section{TEDAVI YAKLAŞIM VE SONUÇLARI}

Literatürde koronoid kırıkları üzerine yapılan çalışma sayısı sınırlıdır. Bunun temel nedeni, koronoid kırığının sıklıkla kompleks dirsek kırıklı çıkıklarının bir komponenti olması ve bu yaralanmaların seyrek olarak görülmesidir. Diğer taraftan son yıllarda dirsek çıkığı, mediyal kollateral bağ hasarı, radius başı ve koronoid kırığından oluşan 'korkunç üçlü' yaralanması üzerinde araştırmalar yoğunlaşmıştır. ${ }^{[4,8,9]} \mathrm{Bu}$ yaralanmalarda önem verilen nokta, dirseğin ana stabilizatörü olduğu düşünülen mediyal kollateral bağın hasarıdır. Bir çelişki olarak, lateral kollateral bağ bütünlüğünün bozulduğu ancak mediyal kollateral bağın ön demetinin sağlam olduğu yaralanmalarda da dirseğin çıkabileceği gösterilmiştir. ${ }^{[10]}$ Bununla birlikte, 'korkunç üçlü' yaralanmalarının tedavisinde, radius başı ile koronoid kırı̆̆ı ve lateral kollateral bağ tamirinin stabilite sağlamaya yeterli olacağı, ek olarak mediyal kollateral bağ tamirinin stabiliteye önemli bir ek katkısı olmadığı vurgulanmıştır. ${ }^{[11,12]}$

'Korkunç üçlü' yaralanması dışında koronoid fragmanı içeren kompleks proksimal ulnar kırıkların eşlik ettiği dirsek kırıklı çıkıklarını inceleyen mevcut çalışma sayısı azdır. Regan ve Morrey'in serisinde Tip III koronoid kırı̆ğ bulunan beş hastadan üçünde (\%60) birlikte proksimal ulna kırıklarının bulunduğu ve bu grubun tedavi sonuçlarının, basit yaralanmaları olan gruba göre eklem hareketi ve ağrı açısından anlamlı derecede kötü olduğu bildirilmiştir. ${ }^{\left[{ }^{[3]}\right.}$ Monteggia kırığı olan 48 hastanın incelendiği benzer bir seride, eşlik eden Bado Tip II yaralanması (posterior/posterolateral) olan 10 hastanın tedavi başarısının düşük olduğu izlenmiştir. ${ }^{[13]}$ Bu gruptaki komplikasyonlar arasında instabilitenin devamı ile birlikte iki hastada proksimal radyoulnar sinostoz ve üç hastada koronoid fragman redüksiyonunun yetersizliğine ikincil, post-travmatik osteoartrit gelişimi bildirilmiştir. Bu bulgular, kompleks dirsek travmalarında eşlik eden kırıklar ve koronoid fragmanın büyüklüğü arttıkça tedavi başarısının azaldığına işaret etmektedir.

Parçalı proksimal ulna kırığı olan 18 hastanın incelendiği bir seride Rochet ve arkadaşları, çift plak tekniği ile tedavi sonuçlarını bildirmişlerdir. ${ }^{[14]}$ Sonuç olarak, üç hastada önemli komplikasyon izlenmiştir (iki kaynamama ve bir dirsek çıkı̆̆ı) ve bu komplikasyonların tümü, eşlik eden koronoid kırığı bulunan 11 hastayı içeren grupta ortaya çıkmıştır. Dornberg ve arkadaşlarının olekranon kırıklı-çıkıkları bulunan 26 hastayı (10 anterior ve 16 posterior çııı) değerlendirdikleri başka bir seride, 16 hastada eşlik eden koronoid kırı̆ğ görülmüş ve bunların 10'u vida ile tespit edilmiştir. ${ }^{[7]}$ Koronoid stabilizasyonu uygulanmayan hastaların tümünde kaynamama ve instabiliteye bağlı erken artroz gelişimi izlenmiştir. Bu veriler, koronoid fragmanın uygun redüksiyon ve osteosentezinin tedavi başarısı için kritik bir öneme sahip olduğunu göstermektedir.

AO (Association for Osteosynthesis) grubuna ait dirsek bölgesi radius ve ulna kırıklarının yer aldığı 120 olgudan oluşan geniş bir derlemede, tedavi sonrası komplikasyonlar bildirilmiştir. ${ }^{[15]}$ Koronoid ve radius başı kırığı bulunan 25 hastanın 11'ine radius başı rezeksiyonu uygulanmış ve bu gruptaki sekizer hastada erken artroz ve valgus instabilitesi gelişimi gözlenmiştir. Bu sonuçlarla koronoid redüksiyonunun dirsek stabilitesi için çok önemli olduğu ve dirsek instabilitesinin bulunduğu durumlarda radius başı rezeksiyonunun kontrendike olduğu sonucuna varılmıştır. Böyle durumlarda koronoid kırı̆ııın stabilizasyonuna ek olarak radius başının tespiti veya protez ile replasmanı ve lateralkollateral bağ tamiri önerilmektedir. ${ }^{[12]}$

Koronoid fragmanın tespit edilemeyecek kadar çok parçalı veya erode olduğu kronik post-travmatik olgularda, dirsek stabilitesinin sağlanması için koronoid rekonstrüksiyonu gerekir. Ancak bu konuda ideal bir seçenek yoktur ve halihazırda koronoid protezleri bulunmamaktadır. Koronoid yetmezliğine eşlik eden çok parçalı radius başı kırığı olan ve protez replasmanı uygulanacak olgularda, radius başı rekonstrüksiyonu için otogreft olarak kullanılabilir. ${ }^{[16]}$ Radius başı kullanımının mümkün olmadığı durumlarda ise olekranon ucu, osteokondral otogreft olarak tercih edilebilir. Biyomekanik ve klinik çalışmalarda uygulanan bu tekniğin dezavantajı, sadece belli bir büyüklüğe kadar olan defektlerde başvurulabilmesidir. ${ }^{[17,18]}$ Olekranon ucundan alınacak parçanın dirsek instabilitesi yaratması nedeniyle bu teknik, büyük koronoid defektlerinde uygulanmamalıdır. ${ }^{[19]}$ Bunlara ek olarak, iliak kanat otogrefti, ${ }^{[20]}$ kostal osteokondral otogreft, ${ }^{[21]}$ radius başı allogrefti ${ }^{[16]}$ ve biseps tendonunun korakoid basisine transferi ile gerçekleştirilen yumuşak doku rekonstrüksiyonu, ${ }^{[22]}$ koronoid yetmezliklerinin tedavisi için literatürde tanımlanan, ancak etkinlikleri daha geniş ve uzun takipli çalışmalarla değerlendirilmesi gereken diğer rekonstrüksiyon seçenekleridir. 


\section{SONUÇ}

Koronoid çıkıntı, dirsek stabilitesini sağlayan önemli bir kemik yapıdır. Koronoid kırıklarının anatomik redüksiyon ve tespiti, tedavi sonrası dönemde oluşabilecek instabilite ve post-travmatik artroz gelişimini önlemede ve tedavi başarısını arttırmada kritik bir öneme sahiptir.

\section{AÇIKLAMA}

Bu yazının hazırlanması aşamasında hasta hakları ile ilgili her türlü etik ve yasal kurallara uyulmuştur. Yazıyı hazırlayan yazarlar, hazırlık ve yazım aşamalarında herhangi bir kuruluş/firmadan maddi bir destek/yardım almamıştır.

\section{KAYNAKLAR}

1. Regan WD, Morrey BF. Coronoid process and Monteggia fractures. In: Morrey BF, editor. The elbow and its disorders. 3rd ed. Philadelphia, PA: W.B. Saunders; 2000. p.396-408.

2. Amis $\mathrm{AA}$, Miller $\mathrm{JH}$. The mechanism of elbow fractures: an investigation using impact tests in vitro. Injury 1995;26(3):163-8.

3. Closkey RF, Goode JR, Kirschenbaum D, Cody RP. The role of the coronoid process in elbow stability. A biomechanical analysis of axial loading. J Bone Joint Surg Am 2000;82-A(12):1749-53.

4. Morrey BF, An KN. Articular and ligamentous contributions to the stability of the elbow joint. Am J Sports Med 1983;11(15):315-9.

5. Regan W, Morrey B. Fractures of the coronoid process of the ulna. J Bone Joint Surg Am 1989;71(9):1348-54.

6. O'Driscoll SW, Jupiter JB, Cohen MS, Ring D, McKee MD. Difficult elbow fractures: pearls and pitfalls. Inst Course Lect 2003;52:113-34.

7. Doornberg J, Ring D, Jupiter JB. Effective treatment of fracture-dislocations of the olecranon requires a stable trochlear notch. Clin Orthop Relat Res 2004;(429):292-300.

8. Ring D, Jupiter JB, Zilberfarb J. Posterior dislocation of the elbow with fractures of the radial head and coronoid. J Bone Joint Surg Am 2002;84-A(4):547-51.
9. Josefsson PO, Gentz CF, Johnell O, Wendeberg B. Dislocations of the elbow and intraarticular fractures. Clin Orthop Relat Res 1989;(246):126-30.

10. O'Driscoll SW, Morrey BF, Korinek S, An KN. Elbow subluxation and dislocation. A spectrum of instability. Clin Orthop Relat Res 1992;(280):186-97.

11. Rosell P, Clasper J. Roles of the medial collateral ligament and the coronoid in elbow stability. J Bone Joint Surg Am 2003;85-A(3):568.

12. Pugh DM, Wild LM, Schemitsch EH, King GJ, McKee MD. Standard surgical protocol to treat elbow dislocations with radial head and coronoid fractures. J Bone Joint Surg Am 2004;86-A(6):1122-30.

13. Ring $D$, Jupiter JB, Simpson NS. Monteggia fractures in adults. J Bone Joint Surg Am 1998;80(12):1733-44.

14. Rochet S, Obert L, Lepage D, Lemaire B, Leclerc G, Garbuio P. Ostéosynthèse des fractures comminutives de l'ulna proximal par deux plaques. Revue de Chirurgie Orthopédique et Traumatologique 2010;96(7):800-7. CrossRef

15. Heim U. Combined fractures of the radius and the ulna at the elbow level in the adult. Analysis of 120 cases after more than 1 year. Rev Chir Orthop Reparatice Appar Mot 1998;84(2):142-53.

16. vanRiet RP, Morrey BF, O'Driscoll SW. Use of osteochondral bone graft in coronoid fractures. J Shoulder Elbow Surg 2005;14(5):519-23.

17. Schneeberger AG, Sadowski MM, Jacob HA. Coronoid process and radial head as posterolateral rotatory stabilizers of the elbow. J Bone Joint Surg Am 2004;86-A(5):975-82.

18. Moritomo H, Tada K, Yoshida T, Kawatsu N. Reconstruction of the coronoid for chronic elbow dislocation of the elbow. Use of a graft from the olecranon in two cases. J Bone Joint Surg Br 1998;80(3):490-2.

19. An KN, Morrey BF, Chao EY. The effect of partial removal of proximal ulna on elbow constraint. Clin Orthop Relat Res 1986;(209):270-9.

20. Kohls-Gatzoulis J, Tsiridis E, Schizas C. Reconstruction of the coronoid process with iliac crest bone graft. J Shoulder Elbow Surg 2004;13(2):217-20.

21. Damiani M, King GJW. Coronoid and radial head reconstruction in chronic posttraumatic elbow subluxation. Inst Course Lect 2009;58:481-93.

22. King T. Recurrent dislocation of the elbow. J Bone Joint Surg $\mathrm{Br}$ 1953;35-B(1):50-4. 